\title{
micromachines
}

ISSN 2072-666X

www.mdpi.com/journal/micromachines

Article

\section{MEMS-Based Boiler Operation from Low Temperature Heat Transfer and Thermal Scavenging}

\author{
Suvhashis Thapa, Emmanuel Ogbonnaya, Christopher Champagne and Leland Weiss * \\ Department of Mechanical Engineering, Louisiana Tech University, PO Box 10348 Ruston, \\ LA 71272, USA; E-Mails: tsuvhashis@yahoo.com (S.T.); eog002@latech.edu (E.O.); \\ cchamp4@gmail.com (C.C.) \\ * Author to whom correspondence should be addressed; E-Mail: lweiss@latech.edu; \\ Tel.: +1-318-257-5113; Fax: +1-318-257-5104.
}

Received: 16 March 2012; in revised form: 31 March 2012 / Accepted: 18 April 2012 /

Published: 26 April 2012

\begin{abstract}
Increasing world-wide energy use and growing population growth presents a critical need for enhanced energy efficiency and sustainability. One method to address this issue is via waste heat scavenging. In this approach, thermal energy that is normally expelled to the environment is transferred to a secondary device to produce useful power output. This paper investigates a novel MEMS-based boiler designed to operate as part of a small-scale energy scavenging system. For the first time, fabrication and operation of the boiler is presented. Boiler operation is based on capillary action that drives working fluid from surrounding reservoirs across a heated surface. Pressure is generated as working fluid transitions from liquid to vapor in an integrated steamdome. In a full system application, the steam can be made available to other MEMS-based devices to drive final power output. Capillary channels are formed from silicon substrates with $100 \mu \mathrm{m}$ widths. Varying depths are studied that range from 57 to $170 \mu \mathrm{m}$. Operation of the boiler shows increasing flow-rates with increasing capillary channel depths. Maximum fluid mass transfer rates are $12.26 \mathrm{mg} / \mathrm{s}$ from $170 \mu \mathrm{m}$ channels, an increase of $28 \%$ over $57 \mu \mathrm{m}$ channel devices. Maximum pressures achieved during operation are $229 \mathrm{~Pa}$.
\end{abstract}

Keywords: MEMS; micro heat engine; phase change; boiler; free piston; scavenging; micro heat transfer 


\section{Introduction}

Pressing energy concerns and growing rates of worldwide energy consumption present a need for focused research on thermal energy scavenging and power production from renewable sources. In 2010 the United States consumed 98 quadrillion BTUs (British Thermal Units) of energy [1]. The U.S. Department of Energy has further predicted that global energy consumption will increase by $44 \%$ compared to 2006 levels [2]. Of particular concern is the operating efficiency of many standard cycles. The Otto cycle, for example, exhibits an approximate efficiency of 35\% [3]. The remaining two thirds of initial fuel energy is expelled into the surrounding environment as waste thermal energy from either exhaust or heat exchanger devices. This is of particular concern as transportation sources account for nearly $30 \%$ of total energy consumed in the U.S. on an annual basis [1]. Other sectors of energy consumption produce large amounts of waste thermal energy as part of their regular operation as well.

The work in this paper presents investigations of a unique phase-change based steam system designed to capture waste heat from some of the sources noted previously. The use of this normally wasted energy provides an overall efficiency enhancement for the larger process as a whole. The system is designed around small-scale, microfabricated devices that may operate across the low temperature gradients commonly associated with waste thermal energy sources. As an added benefit, the devices developed as part of this waste heat scavenging effort are equally well suited to exploit other sources of environmental thermal energy. These include solar thermal sources [4].

Micro-devices and engines have been under investigation by a wide variety of research groups for a number of years. One of the first engines was a micro steam engine constructed by Sandia National Labs in 1993 [5]. Since then, efforts have expanded to include micro steam turbines operating on the Rankine cycle [6,7]. There has also been interest in micro engines operating on the Brayton and Wankel cycles [8-11]. One challenge to many of these approaches has been the nature of high speed rotating components when implemented on the micro scale. High speed stability and bearing tolerance are among the engineering and fabrication challenges. Nonetheless, progress continues on these unique devices [7]. Other micro-engine concepts have relied on power output that does not yield rotary motion. Work by Weiss et al. included a flexing-expander membrane-based device that outputs power via membrane expansion [12-14]. The device consisted of two membranes, separated by a gasket and filled with working fluid that boils at low temperature. When thermal energy was applied, the working fluid expanded causing membrane expansion and power output. This device represented a thermodynamically closed operating cycle, where no working fluid crossed the boundaries established by the device volume. Thermal energy was introduced in discrete applications through the inclusion of a novel thermal switch $[15,16]$.

This present work investigates the operation of a system in an open thermodynamic cycle. The complete system is shown in Figure 1. In its final form, low temperature waste heat (or thermal energy from another source) is consumed by the system boiler where working fluid transitions from liquid to vapor. The resulting pressurized vapor is expanded by a unique Free Piston Expander (FPE) to produce the work output from the system. Expanded working fluid is cooled via heat exchanger and then returned to the boiler for reuse. In this manner, the system represents a modified Rankine Cycle which lacks the typical rotary expansion and high operating temperature. 
Figure 1. System overview (FPE—Free Piston Expander).

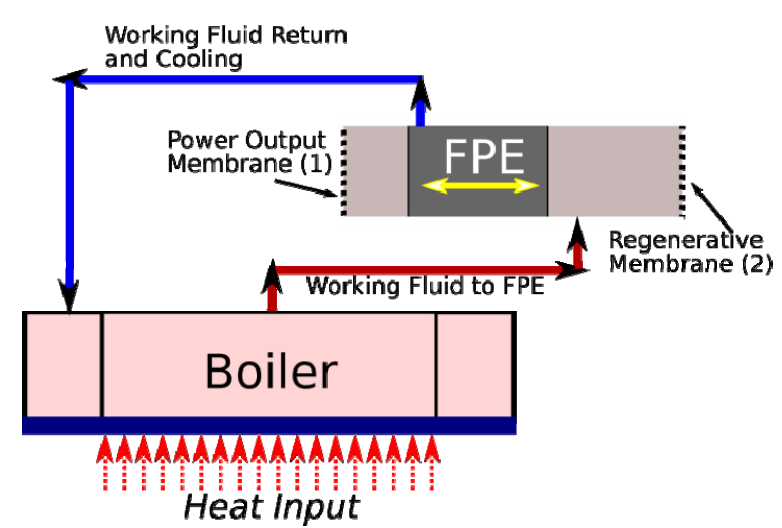

The boiler and FPE are uniquely designed components of this system. The FPE has been modeled and discussed in previously published work [17]. The free piston (noted as "FPE" in Figure 1) slides linearly within a bore based on input pressure from the system boiler. As the piston slides, it expands the working fluid and pressurizes the primary power output membrane. Once fully expanded, the vapor is released to the cooling line and the piston begins its return to the starting position. The return is driven by energy stored within the primary membrane. The secondary, regenerative membrane helps absorb piston energy during the return stroke and aids in the overall efficiency of the system through this unique regenerative capture. The action of the membranes constitutes the system power output and is designed to produce either mechanical or electrical power. Electrical power may be created through the actuation of an external PZT cantilever or similar device. Mechanical power output is achievable through direct membrane mechanical action. Figure 2 shows an early FPE bore.

Figure 2. FPE prototype bore.

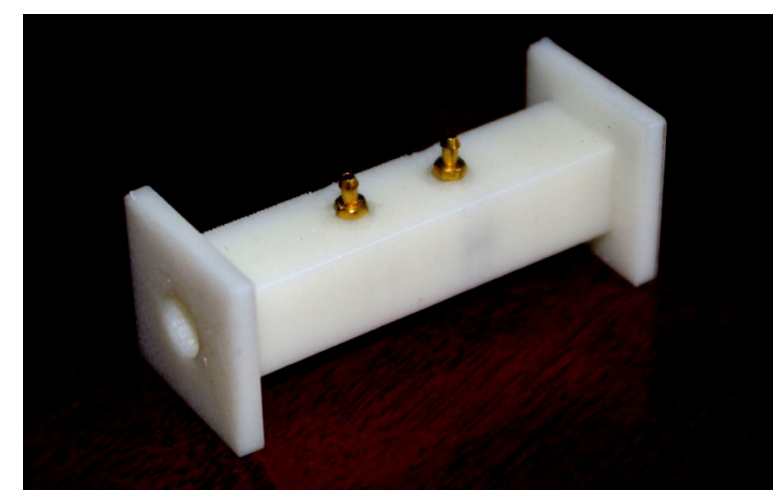

The boiler is the particular focus of this present work. Like the FPE, the boiler is a unique design for low temperature application. The design focuses on the ability to generate working fluid pressure with minimal moving parts or components common to large-scale steam systems or true Rankine cycle devices on the microscale. This paper represents the first time a boiler of this type has been produced via MEMS techniques and operated at pressurized conditions. Figure 3 illustrates the boiler concept.

Operation of the boiler is dependent on capillary action of the working fluid across the heated lower surface as noted in Figure 3. This capillary action is based on the microfabrication of capillary channels that take working fluid from the surrounding fluid reservoirs, providing a continuous source of working fluid supply to the heated surface. The top of the boiler is enclosed with a steamdome to 
provide a central collection point for vaporized working fluid. From the steamdome, the pressurized working fluid is available to devices like the FPE in the final assembly of the overall system.

Figure 3. Boiler design.

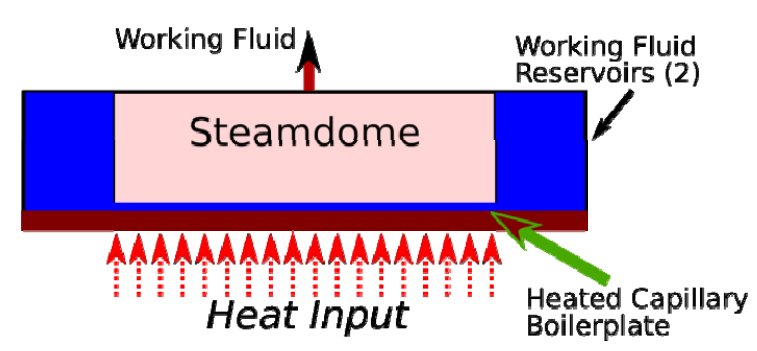

The overall approach to this low-temperature energy challenge has several advantages including ease of fabrication due to the lack of high speed bearings or rotating parts. Operation of the device at temperatures typical of environmentally scavenged waste heat allows a wide degree of flexibility in material selection as well. The remainder of this work discusses the fabrication and characterization of the boiler. Reported testing considers variations like channel dimension, power input, temperature of operation, and generated working fluid pressure and fluid flows.

\section{Experimental Section}

This section discusses the fabrication and test procedures for the capillary boiler. Specific microfabrication processes as well as test setups and procedures are reviewed.

\subsection{Fabrication}

Boilers were constructed of two primary components: a silicon-based boilerplate and an acrylic-based steamdome with volumes for working fluid reservoirs. A silicon substrate formed the basis for each of the boilerplates. Fabrication of the individual boilerplates focused on typical MEMS fabrication processes conducted in a cleanroom environment. Each had an overall size of $13 \mathrm{~mm}$ in width by $38 \mathrm{~mm}$ in length. This included the primary phase change/heat exchange area as well as area for the working fluid reservoirs at either end as noted in Figure 3. Figure 4 shows a completed boilerplate.

Figure 4. Completed boilerplate.

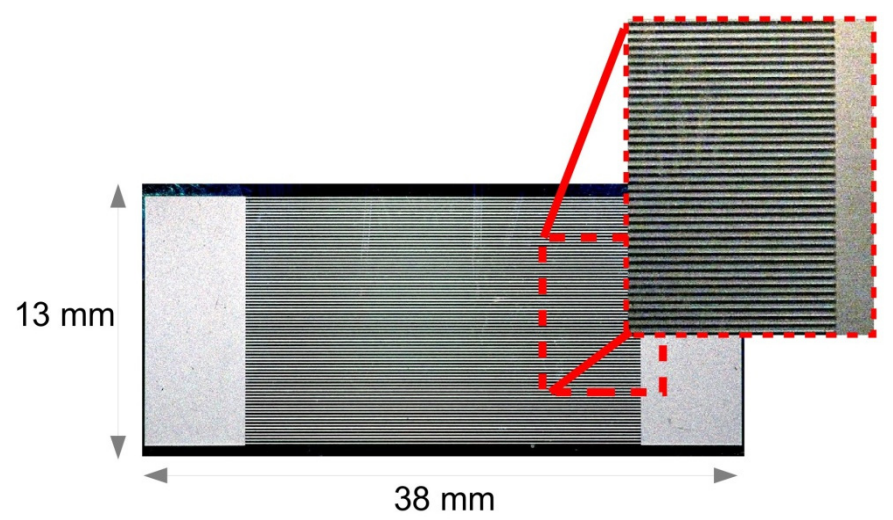


Standard $400 \mu \mathrm{m}$ thick, double-side polished $<100>$ silicon wafers served as the base for boiler fabrication. Boilers required the manufacture of capillary channels extending between the working fluid reservoirs. Boilers were fabricated with a range of channel depths as part of this work. Previous work established the ability to vary capillary pumping rates as a function of capillary channel height and width dimensions $[12,18]$. Due to this effect, multiple channel heights were fabricated to fully characterize boiler behavior as a result of capillary pumping variations. Despite changing channel depths, channel widths were maintained at $100 \mu \mathrm{m}$ to facilitate consistent comparison across boiler designs. Overall channel lengths were $25.5 \mathrm{~mm}$ centered on the boilerplate between reservoirs. Figure 4 shows the top-down view of a completed boilerplate and microchannels.

Channel fabrication was achieved by two different fabrication techniques. For depths below $100 \mu \mathrm{m}$, photoresist was spun and patterned atop the silicon wafer in preparation for Reactive Ion Etch (RIE). This produced a photoresist mask in the desired channel pattern atop the silicon wafer. Different channel depths were achieved by varying the RIE exposure time. For fabrication of channels with depths of $100 \mu \mathrm{m}$ and greater an alternate procedure was used. First, e-beam evaporation was used to deposit a chrome layer atop the silicon wafer to a depth of $200 \mathrm{~nm}$. Photoresist was used to pattern the chrome layer, deposited in a standard spin-coating procedure. Once fully developed, the wafer was placed into chrome etchant to create the final chrome RIE mask utilized to form channels. The chrome proved a more durable mask compared to the photoresist and was able to withstand longer durations of RIE exposure. This allowed the formation of channels with depths greater than $100 \mu \mathrm{m}$. Following RIE, any remaining chrome was removed via chrome etchant.

After channels were etched into the silicon wafer, individual boilerplates were diced from the wafer and were ready for incorporation with the acrylic steamdome. Four channel depths were investigated as part of this work. These included depths of 57, 100, 150, and $170 \mu \mathrm{m}$.

For each boilerplate manufactured using these processing steps, a top steamdome was added as noted in Figure 3. This acrylic top piece was designed to fit directly over the boilerplate and provide working fluid reservoirs aside the capillary channels. In addition, the central volume of the acrylic piece was left open to serve as a central steam collection point, or steamdome, over the primary boiler channels. $3 \mathrm{~mm}$ thick inner walls separated the steamdome from reservoirs with only the boilerplate capillary channels running beneath. Acrylic steamdomes were fabricated using a casting technique where a single prototype was used to form a rubber mold. A two-part liquid resin from Alumilite Corporation was mixed and used to fill the rubber mold. The mixture was allowed to cure for several hours before removal from the mold. This technique produced domes with good repeatability and uniformity. The overall size of the steamdomes (including reservoirs) was $13 \mathrm{~mm}$ by $38 \mathrm{~mm}$ by $10 \mathrm{~mm}$ in height. Small holes were drilled in the top of the acrylic piece. A 1/16" OD hole was drilled atop the reservoir openings to facilitate the addition of working fluid during testing. A larger 1/8" OD hole was drilled atop the main dome outlet and a brass nipple fitting from McMaster-Carr was epoxied in place. This allowed thermocouples and a small pressure sensor to attach to each fully assembled device. 3/16" OD tubing was used for these connections. Following these additional fabrication steps, each acrylic steamdome was permanently epoxied to a silicon boilerplate. This readied the boiler for testing. Figure 5 shows a steamdome and boilerplate, ready for incorporation of sensors and full testing. 
Figure 5. Steamdome and boilerplate.

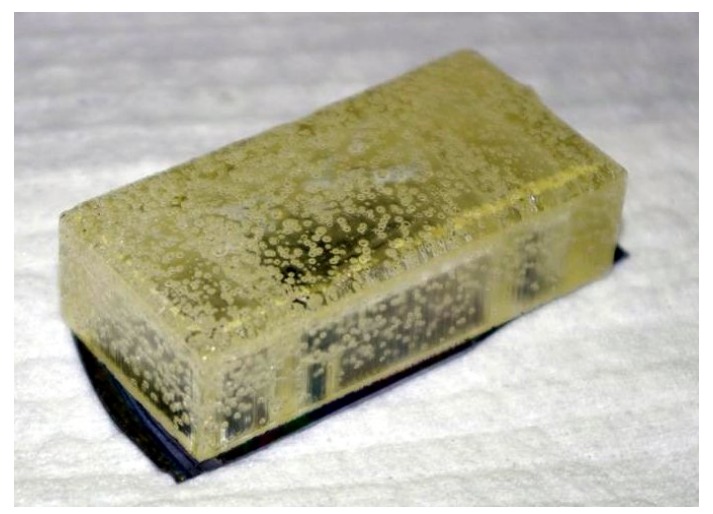

\subsection{Test Setup}

Testing of the assembled boilers was conducted based on the boiler's ability to generate working fluid phase change and pressure as a function of input power. The fabricated capillary channels were critical to the operation of the boiler and the generation of a fluid pumping effect. Boilers with varying channel depths were tested and characterized based on these operating parameters.

A common setup was utilized for each boiler tested. In addition, each assembled boiler was tested multiple times to ensure accurate reporting of operating characteristics. The working fluid utilized in these tests was $3 \mathrm{M}^{\mathrm{TM}}$ HFE-7200. This working fluid was selected for multiple reasons. First, the fluid and channels presented a high degree of wetting, suitable for capillary action. The use of other fluids could vary measured pumping rates and boiler effectiveness depending on fluid-surface contact angle and resulting capillary forces. Other types of fluids would have to be evaluated using this performance metric. Second, the working fluid presents a low boiling point of $76^{\circ} \mathrm{C}$ at atmospheric pressure. This is appropriate for many waste heat applications that output thermal energy to the environment at relatively low temperatures. It is important to recognize, however, that the boiler and overall micro-system is not fluid specific. Operation of the system may be tailored to specific thermal sources through a change in working fluid with different boiling point. A final benefit of this working fluid is the small environmental impact potential in any real-world application.

Several components were added to assembled boilers to fully monitor and characterize the performance. Boiler operation involved the use of heat addition via a resistance heater. This heater substituted for potential waste heat sources in a real-world application. The heater was a KHLV-101/P from Omega Engineering. This was hooked to a DC power supply. Both voltage and current consumption were monitored allowing determination of power input to the boiler during testing. A thermocouple (T/C) was added within the boiler steamdome to monitor operating temperature of vapor within the boiler. An additional T/C was located on the heater to measure input temperature. Both thermocouples were k-type, purchased from Omega Engineering. Finally a Precision-Measurements Co (PMC) \#060 pressure transducer was incorporated above the steamdome to measure the operating pressure of the boiler. Figure 6 shows the fully assembled boiler and test hardware. The pressure transducer was located as part of the central steamdome exit. 
Figure 6. Boiler test setup.

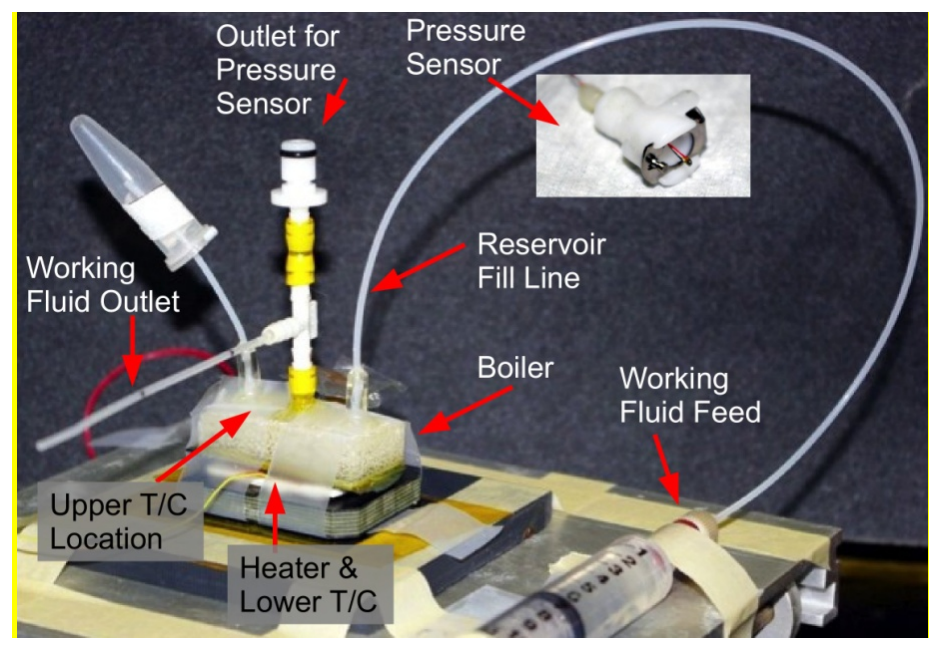

Two basic tests were performed to fully characterize boiler performance. The first allowed vaporized working fluid to freely exit the boiler in an atmospheric condition. This produced results that indicated capillary channel effectiveness directly when assembled with the steamdome. This technique did not produce pressure within the boiler, however. Based on the performance of boilers operating at atmospheric condition, a second test was performed that restricted the exit tube to allow the boiler to operate at a higher pressure. The boiler selected for pressurized operation showed the best performance during atmospheric testing. These second tests produced true boiler-type output consisting of pressurized fluid flow. The direct operating procedure for both tests was similar.

In each test, thermal energy was applied to the boiler for several minutes without working fluid present. This thermal energy simulated heat transfer from a real-world source. This allowed the boiler to achieve a steady state condition prior to working fluid addition. Power inputs considered for these tests were $2.6 \mathrm{~W}$ and $3.6 \mathrm{~W}$ as measured at the resistance heater. This maintained boiler operation within or below an envelope of thermal input consistent with potential real-world sources. Tests conducted at elevated pressures considered only the elevated input of 3.6 W. Steady state operation was determined by monitoring thermocouple readout. After achieving steady state, the boiler was loaded with working fluid via syringe connected to the working fluid reservoirs as noted in Figure 6. This provided the needed working fluid to the capillary channels for phase change. The feed was connected via sealed connection to prevent any pressurized working fluid generated by the boiler from backing into the working fluid syringe feed. In this manner, vapor was forced to exit the centrally located steamdome hole.

Fluid was supplied in two ways depending on the type of test being conducted. For testing conducted in atmospheric conditions, experiments were conducted that illuminated the basic capillary flow rate capabilities of the boilers. To achieve this, reservoirs surrounding the boilerplate were slightly oversupplied to allow the capillary channels a maximum amount of fluid for phase change. By contrast, tests conducted under pressurized conditions used these achieved capillary flows as a guideline and did not oversupply working fluid. This had the desirable effect of focusing boiling and phase change within the channels during pressurized tests. This also eliminated potential pool boiling resulting from over-full conditions. In both cases, a syringe pump was sourced to predictably compress the supply syringe. This maintained working fluid within the boiler at controllable and predictable levels. 
Further advantages of syringe pump use included elimination of large-scale temperature fluctuations caused by unpredictable supply. In addition, operation in this manner represented an improved approximation of boiler operation as part of a larger system. In a full system, working fluid would be returned to the boiler at predictable rates based on the boiler output flow rates and consumption by any attached power output device.

Independent of test type, following the addition of working fluid the boiler was allowed to operate at a new steady state operating condition. As with the initial dry "warmup," this new steady state condition was determined based on a consistent operating temperature of the boiler. Figure 7 shows a typical temperature plot from within the steamdome following the addition of working fluid. The constant temperature section represented the period considered for testing and analysis presented in this paper. Individual tests were conducted using boilerplates with capillary channels of 57, 100, 150, and $170 \mu \mathrm{m}$ depth. Outcome from these tests represented a significant characterization of boiler operation across multiple power inputs using multiple designs.

Figure 7. Typical temperature plot and test section.

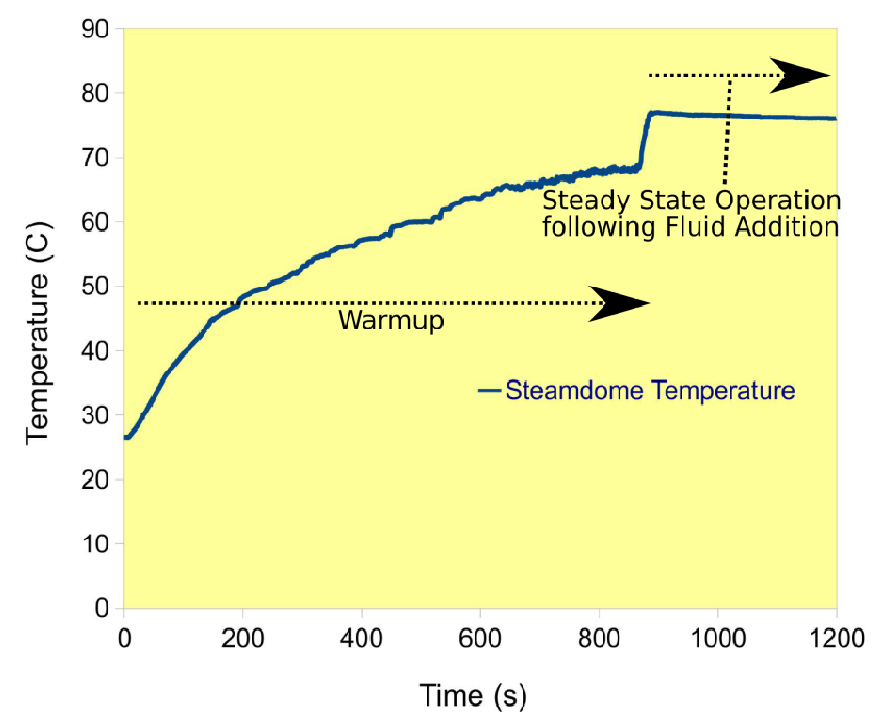

Independent of test type, vaporized working fluid was allowed to exit the boiler via the central steamdome hole in line with the pressure transducer. The working fluid was directed into a short length of tubing. For atmospheric testing, focused primarily on capillary channel effectiveness within the steamdome, the condensed working fluid was collected within a syringe. The total volume was measured as a function of test duration yielding specific flow rate information. This mass flow rate was combined with the known heat of vaporization for HFE 7200, $125 \mathrm{~kJ} / \mathrm{kg}$ at atmospheric pressure. This allowed determination of power absorption via phase change of the working fluid.

Following tests within the atmospheric pressure steamdome, pressurized testing was conducted. The boiler was brought to a dry, steady state condition as before and the syringe pump was allowed to input working fluid to the reservoirs as previously described. A restriction in the form of a clamping force was placed on the central exit tube to increase the boiler operating pressure. This effectively simulated operation when the boiler must generate operating pressure for attached devices. The boiler was operated for an additional several minutes and allowed to come to a steady state under these new conditions. Based on previously established guidelines, the feed rate of the syringe pump was adjusted 
as needed such that working fluid levels within the boiler were maintained at a constant value. Given a change in operating pressure, the feed rate was adjusted accordingly to ensure no oversupply and pool boiling. This was confirmed both visually and via pressure and thermocouple readout. In this manner, the boiler was operated at a steady, pressurized condition with a known mass flow rate from the working fluid supply. By varying the clamping force, different operating pressures were achieved and capillary action was forced to work against generated boiler pressures. Power input was maintained at $3.6 \mathrm{~W}$ for pressurized tests.

Independent of test type, T/C and pressure sensor readouts were recorded via Labview software. This raw data was post-processed to formulate the final test results.

\section{Results and Discussion}

Tests were conducted as described in Section 2. These tests resulted in determination of individual boiler operation based on both heat input and boilerplate channel design. In the first set of tests, the boiler was allowed to operate at an atmospheric pressure condition where no restriction was placed on the main exit tube. In the second test, a restriction was in place and the boiler was operated at elevated pressures. First, results are reported for the atmospheric system given $2.6 \mathrm{~W}$ input. Second, atmospheric results from 3.6 W input are reported. Finally, operation of the boiler at elevated pressure is reported. Key measurements recorded during testing were the working fluid mass flow rate, the operating pressure of the boiler, temperature of the simulated thermal source as provided by the resistance heater, and internal steamdome operating temperature of the vapor. Tables 1 and 2 summarize atmospheric operation of the boiler. Mass flow measurement error was determined to be on the order of $\pm 2.5 \mu \mathrm{g} / \mathrm{s}$ given the accuracy of measurements employed.

Table 1. Atmospheric boiler operation at $2.6 \mathrm{~W}$ thermal input.

\begin{tabular}{cccc}
\hline $\begin{array}{c}\text { Channel Depth } \\
(\boldsymbol{\mu m})\end{array}$ & $\begin{array}{c}\text { Source Temperature } \\
\left({ }^{\circ} \mathbf{C}\right)\end{array}$ & $\begin{array}{c}\text { Steamdome Vapor } \\
\text { Temperature }\left({ }^{\circ} \mathbf{C}\right)\end{array}$ & $\begin{array}{c}\text { Mass Flow } \\
(\mathbf{m g} / \mathbf{s})\end{array}$ \\
\hline 57 & 94.2 & 74.3 & 4.53 \\
100 & 106.9 & 74.8 & 4.56 \\
150 & 101.5 & 75.8 & 4.61 \\
170 & 103.4 & 76.2 & 4.61 \\
\hline
\end{tabular}

Table 2. Atmospheric boiler operation at $3.6 \mathrm{~W}$ thermal input.

\begin{tabular}{cccc}
\hline $\begin{array}{c}\text { Channel Depth } \\
(\boldsymbol{\mu m})\end{array}$ & $\begin{array}{c}\text { Source } \\
\text { Temperature }\left({ }^{\circ} \mathbf{C}\right)\end{array}$ & $\begin{array}{c}\text { Steamdome Vapor } \\
\text { Temperature }\left({ }^{\circ} \mathbf{C}\right)\end{array}$ & $\begin{array}{c}\text { Mass Flow } \\
(\mathbf{m g} / \mathbf{s})\end{array}$ \\
\hline 57 & 105.3 & 74.6 & 8.86 \\
100 & 121.6 & 75.9 & 10.66 \\
150 & 116.2 & 76.1 & 11.47 \\
170 & 120.5 & 76.1 & 12.26 \\
\hline
\end{tabular}

Several observations may be made based on these initial runs. First, as expected the varying channel depths exhibit different mass flow rates within the steamdome. This was consistent with other devices and base experimental and modeling activities conducted by Kim et al. [11,16]. A general trend was established where boilers constructed with large channel depths showed increasing internal fluid flow 
resulting in increased rates of phase change. Given $2.6 \mathrm{~W}$ input, the mass flow was increased by $1.7 \%$ when channels increased from $57 \mu \mathrm{m}$ depth to $170 \mu \mathrm{m}$ depth. These effects were amplified at increased thermal inputs. Given $3.6 \mathrm{~W}$ input, mass flow increased by nearly $28 \%$ as channel depth increased from 57 to $170 \mu \mathrm{m}$. Figure 8 shows the recorded mass flow rates versus channel depth for the boilers tested.

Figure 8. Mass flow vs. channel depth.

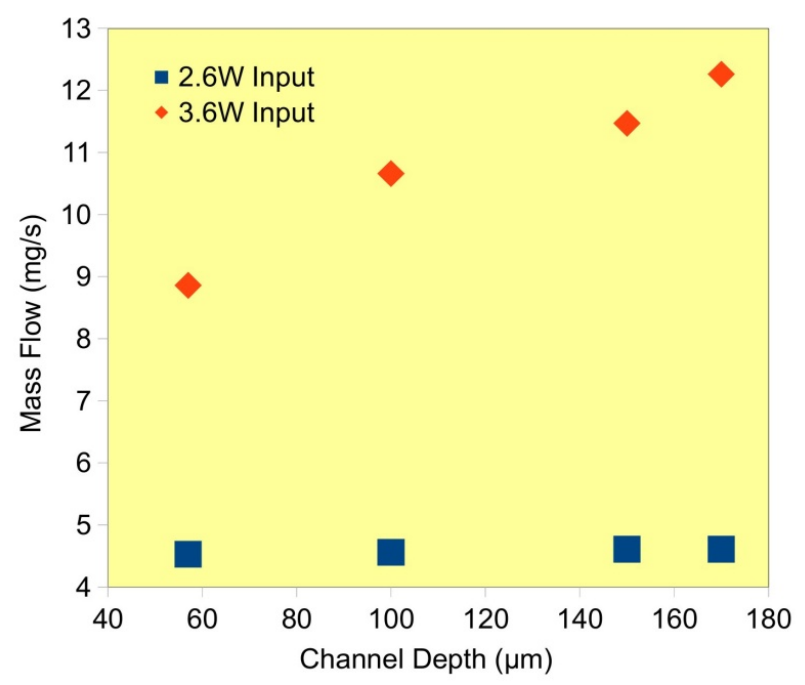

In addition to varying mass flow rates, it is worth noting the operating temperatures inside the steamdome. The $\mathrm{T} / \mathrm{C}$ was positioned such that it was truly suspended within the vapor contents of the steamdome. Readings reflected the boiling point of the working fluid at atmospheric pressure, about $76{ }^{\circ} \mathrm{C}$. This confirmed the saturated environment within the boiler.

Energy absorption via phase change was determined based on these results. Given the working fluid heat of vaporization, $0.57 \mathrm{~mW}$ was consumed by the $57 \mu \mathrm{m}$ boiler given $2.6 \mathrm{~W}$ input. Energy absorption was $0.58 \mathrm{~mW}$ for $170 \mu \mathrm{m}$ channels at the same power input. Amplified trends were observed given $3.6 \mathrm{~W}$ thermal input. Power consumption via phase change was $1.11 \mathrm{~mW}$ for the $57 \mu \mathrm{m}$ channel boiler. $1.53 \mathrm{~mW}$ was consumed by the $170 \mu \mathrm{m}$ channel boiler.

The power consumed via phase change yielded poor conversion efficiencies given the heat transferred to the boiler during testing. This is explained through consideration of the area and thermal mass of the enlarged steamdomes. Although constructed from acrylic-type material, the domes represent a heat sink, allowing fluid to condense before exiting the system via centralized output hole. While an effective means to collect working fluid from the boiler, future designs will work to limit the dome effect on premature condensation within the chamber itself.

This is evidenced by the results. At increased power input, the average temperature of the steamdome walls should be higher due to elevated boilerplate temperatures. This limited the effect of the steamdome as a thermal heat sink. As a result, the boiler showed greatly increased mass transfer independent of channel dimension at these elevated power inputs. In addition, the specific advantages of increasing channel depths were greatly amplified across the range of channels considered.

Following investigations at atmospheric pressure, the outlet from the boiler was restricted. This had the effect of increasing the operating pressure of the boiler for a given heat input. Several combinations 
of pressure and flow rate were examined. Operating pressures were increased in several steps using ambient tests as a baseline (matching atmospheric testing in Table 2). As discussed in Section 2.2, the boiler with $170 \mu \mathrm{m}$ channel depths was selected due to its preferred performance in atmospheric testing. Table 3 shows the operating pressures with associated flow rates and steamdome temperatures recorded during pressurized testing.

Table 3. Boiler operation at increased pressure and 3.6 W input.

\begin{tabular}{cccc}
\hline Channel Depth $(\boldsymbol{\mu m})$ & Steamdome Vapor Temperature $\left({ }^{\circ} \mathbf{C}\right)$ & Mass Flow $(\mathbf{m g} / \mathbf{s})$ & Pressure (Pa) \\
\hline 170 & 75.7 & 12.3 & $0 \mathrm{~g}$ \\
170 & 76.3 & 10.8 & 19.3 \\
170 & 76.7 & 8.6 & 55.0 \\
170 & 78.3 & 5.4 & 229.3 \\
\hline
\end{tabular}

Results of these tests revealed a maximum operating pressure of $229 \mathrm{~Pa}$ given the fluid supply rates. These rates were guided by atmospheric tests and adjusted to ensure pool boiling and over-supply was avoided. Flows were routinely reduced to match the increasing pressure load of the boiler. This makes sense due to the inherent restriction placed on the central steamdome exit hole. The temperature of the vapor within the steamdome was also observed to increase when the boiler was operated at elevated pressure. This correlates to an increasing saturation temperature corresponding to the increased surrounding steamdome pressure. Figure 9 explores this trend directly and illustrates the boiler operating with varying pressure settings. The maximum pressure achieved for this test was $275 \mathrm{~Pa}$, although was not considered as a steady state point for true performance reporting. As pressure varied, the temperature followed these specific pressure fluctuations demonstrating the saturated operating environment achieved within the boiler.

Figure 9. Temperature and steamdome vapor pressure in boiler.

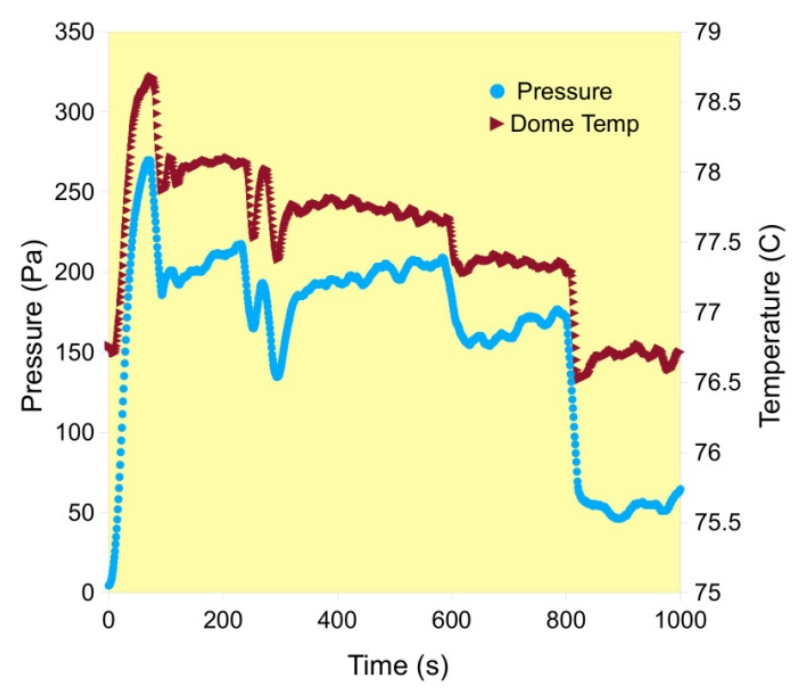

Overall boiler outputs were governed by the same constraints as presented by the steamdome in atmospheric testing. As a result, achieved pressures and flow rates were hampered by the steamdome heat sink. It is fully expected future steamdome redesign efforts will enhance both pressure and mass flow rate capabilities of these devices. 
It is useful to put these tests and thermal inputs into a real world context. Given the boilerplate area, the input amounts resulted in power densities of $5.0 \mathrm{~kW} / \mathrm{m}^{2}$ and $7.8 \mathrm{~kW} / \mathrm{m}^{2}$. These values prove to be conservative estimates compared to potential sources like a typical Otto cycle device. A typical 4 cylinder Otto cycle engine has an expected thermal energy loss directly from the engine sides on the order of $10 \%$ supplied fuel energy [19]. Given an engine output rating of $150 \mathrm{~kW}$, this equates to $45 \mathrm{~kW}$ loss directly to engine surroundings. Using typical dimensions for an engine of this type, this is on the order of $30 \mathrm{~kW} / \mathrm{m}^{2}$. Based on this example, there is clear potential to drive a boiler like those presented in this work. By varying the working fluid, boiler operation may be tuned to specific energy inputs and temperature profiles.

\section{Conclusions}

For the first time, a novel capillary-action based boiler has been fabricated and tested. The design of the boiler is unique, dependent on capillary action to drive fluid flow across the heated boilerplate surface. In this device, heat may be continuously transferred to the boiler from an external source like waste heat or available environmental thermal sources. As part of a complete microfabricated system, useful power may be generated.

Boilerplates were fabricated from silicon substrates with capillary channels of $100 \mu \mathrm{m}$ width. Channel depths were varied as part of these investigations using values of 57, 100, 150, and $170 \mu \mathrm{m}$. Fluid flow rates, operating pressures, and internal working temperatures were monitored during these tests. In atmospheric pressure testing, the best mass transfer recorded was via $170 \mu \mathrm{m}$ channel and $3.6 \mathrm{~W}$ thermal input. The mass transfer rate was $12.26 \mathrm{mg} / \mathrm{s}$ under these conditions. This was an improvement of $28 \%$ compared to boilers constructed with $57 \mu \mathrm{m}$ depth capillary channels. The total power consumed via phase change in these devices was $1.53 \mathrm{~mW}$. Pressurized testing was conducted at pressures ranging from atmospheric to $229 \mathrm{~Pa}$. Boilers with $170 \mu \mathrm{m}$ depth channels were selected for these tests based on their performance in atmospheric conditions. Mass flow rates were varied according to operating pressure, ranging from $12.3 \mathrm{mg} / \mathrm{s}$ at atmospheric pressure to $5.4 \mathrm{mg} / \mathrm{s}$ at $229 \mathrm{~Pa}$.

Several opportunities for improved operation were noted as a result of these tests. The use of the steamdome was an effective method for pressure generation and working fluid collection but resulted in significant cold surface for condensation within the boiler itself. The use of smaller volumes will be investigated in future boiler constructions. There is also significant opportunity to increase the base thermal conductivity of the boilerplate via alternate material investigations and channel constructions. The use of metallic channels, for example, has the potential to increase the net thermal transfer to the working fluid during device operation. These modifications should produce a more efficient system, capable of operation from low-temperature waste heat sources. Despite the challenges noted, this work illustrates the promise of this unique approach to low-exergy energy use using a small-scale microfabricated system.

\section{Acknowledgments}

The authors gratefully acknowledge the support of this work by the NSF via Grant No. ECCS-1053729, and the State of Louisiana Board of Regents. 


\section{References}

1. Energy Information Administration (EIA). Annual Energy Review 2011; Technical Report 2011. Available online: http://www.eia.doe.gov/emeu/aer/contents.html (accessed on 16 March 2012).

2. Annual Energy Outlook 2009 with Projections to 2030; Technical Report DOE/EIA-0383; Department of Energy, National Energy Information Center, EI-30 Energy Information Administration Forrestal Building: Washington, DC, USA, March 2009.

3. Heywood, J.B. Internal Combustion Engine Fundamentals; McGraw-Hill Inc.: New York, NY, USA, 1988; pp. 733-736.

4. Ogbonnaya, E.; Gunasekaran, A.; Weiss, L. Fabrication of a MEMS-based solar thermal collector for energy sustainability. In Proceedings of the 2011 ASME IMECE, Denver, CO, USA, 11-17 November 2011; No IMECE2011-63842, pp. 1-6.

5. Lipkin, R. Micro steam engine makes forceful debut. Sci. News 1993, 144, 197.

6. Lee, C.; Liamini, M.; Frechette, L.G. A silicon microturbopump for a rankine-cycle power-generation microsystem-Part II: Fabrication and characterization. J. Microelectromech. Syst. 2000, 20, 326-338.

7. Lee, C.; Fréchette, L.G. A silicon microturbopump for a rankine-cycle power generation microsystem-Part I: Component and system design. J. Microelectromech. Syst. 2011, 20, 312-325.

8. Muller, N.; Frechette, L. Performance analysis of Brayton and Rankine cycle microsystems for portable power generation. In Proceedings of the 2002 ASME IMECE, New Orleans, LA, USA, 17-22 November 2002; pp. 513-522.

9. Epstein, A.H. Millimeter-scale, micro-electro-mechanical systems gas turbine engines. J. Eng. Gas Turbines Power 2004, 126, 205-226.

10. Lee, C.K.; Jiang, P.; Prewett, P. Design and fabrication of a micro wankel engine using MEMS technology. Microelectron. Eng. 2004, 73-74, 529-534.

11. Epstein, A.H.; Jacobson, S.A.; Protz, J.M.; Frechette, L.G. Shirtbutton-sized gas turbines: The engineering challenges of micro high speed rotating machinery. In Proceedings of the 8th Int'l Symposium on Transport Phenomena and Dynamics of Rotating Machinery (ISROMAC '08), Honolulu, HI, USA, January 2000.

12. Weiss, L.; Richards, C.; Richards, R. Power output force generation by a MEMS phase change actuator. J. Microelectromech. Syst. 2011, 20, 1287-1297.

13. Weiss, L. Resonant operation and cycle work from a MEMS-based micro-heat engine. Microsyst. Technol. 2009, 15, 485-492.

14. Bardaweel, H.K.; Anderson, M.J.; Weiss, L.W.; Richards, R.F.; Richards, C.D. Characterization and modeling of the dynamic behavior of a liquid-vapor phase change actuator. Sens. Actuat. A: Phys. 2009, 149, 284-291.

15. Cho, J.; Wiser, T.; Richards, C.; Bahr, D.; Richards, R. Fabrication and characterization of a thermal switch. Sens. Actuat. A: Phys. 2007, 133, 55-63.

16. Cho, J.; Weiss, L.; Bahr, D.; Richards, C.; Richards, R. Power production by a dynamic micro heat engine with an integrated thermal switch. J. Micromech. Microeng. 2007, 17, S217-S223. 
17. Weiss, L.W. Study of a MEMS-based free piston expander for energy sustainability. J. Mech. Des. 2011, 132, 091002-091008.

18. Kim, D.; Lee, K.; Kwon, T.; Lee, S. Micro-channel filling flow considering surface tension effect. J. Micromech. Microeng. 2002, 12, 236-246.

19. Ferguson, C.; Kirkpatrick, A. Internal Combustion Engines, 2nd ed.; John Wiley and Sons Inc.: New York, NY, USA, 2001.

(C) 2012 by the authors; licensee MDPI, Basel, Switzerland. This article is an open access article distributed under the terms and conditions of the Creative Commons Attribution license (http://creativecommons.org/licenses/by/3.0/). 